\title{
Influência da adubação com nitrogênio e cálcio nas características morfológicas e produtivas das raízes de capim-tanzânia cultivado em solução nutritiva ${ }^{1}$
}

\author{
Cristiane Prezotto Silveira² ${ }^{2}$ Francisco Antonio Monteiro ${ }^{3}$
}

\author{
${ }^{1}$ Projeto apoiado pelo CNPq. \\ 2 Pós-graduanda em Solos e Nutrição de Plantas, ESALQ, Universidade de São Paulo. Caixa Postal 9, CEP: 13418-900, Piracicaba \\ São Paulo, Brasil. Bolsista FAPESP. \\ ${ }^{3}$ Departamento de Ciência do Solo, ESALQ, Universidade de São Paulo. Caixa Postal 9, CEP: 13418-900, Piracicaba, São Paulo, Brasil. \\ Bolsista do CNPq.
}

RESUMO - Avaliaram-se as características radiculares de Panicum maximum Jacq. cv. Tanzânia em resposta a uma solução nutritiva com combinações de doses de nitrogênio e cálcio. Empregou-se quartzo moído como substrato, em um experimento realizado em casa de vegetação no período da primavera, em delineamento de blocos ao acaso, com quatro repetições, em esquema fatorial $5^{2}$ fracionado, com 13 combinações de nitrogênio e cálcio, em mmol/L: 2-0,5; 2-3,0; 2-5,5; 9-1,75; 9-4,25; 16-0,5; 16-3,0; 16-5,5; 23-1,75; 23-4,25; 30-0,5; 30-3,0 e 30-5,5. Após o terceiro corte das plantas, realizou-se a coleta das raízes. A combinação de altas doses de nitrogênio com baixas doses de cálcio proporcionou máximas produções de massa seca e concentração de nitrogênio nas raízes. Os níveis críticos de nitrogênio e cálcio nas raízes do capim-tanzânia foram de 11,07 e $1,30 \mathrm{~g} / \mathrm{kg}$, respectivamente. Coeficientes de correlação significativos foram encontrados para massa seca, comprimento total e superfície total das raízes. O comprimento e a superfície total e o comprimento e a superfície específicos das raízes dependem do suprimento de nitrogênio, não de cálcio. Doses de cálcio exclusivas são determinantes da concentração desse nutriente nas raízes do capim.

Palavras-chave: gramínea forrageira, macronutrientes, Panicum maximum, sistema radicular

\section{Influence of nitrogen and calcium fertilizations on morphological and productive characteristics of tanzania guineagrass roots grown in nutrient solution}

\begin{abstract}
Root traits of Panicum maximum Jacq. Cv. Tanzânia were evaluated in response to a nutritive solution with combinations of nitrogen and calcium rates. Ground quartz was used as substrate in an experiment carried out in a greenhouse in the spring, using a complete randomized block design, with four replications, in a fractionated $5^{2}$ factorial scheme, with 13 combinations of nitrogen and calcium, in mmol/L: 2-0.5; 2-3.0; 2-5.5; 9-1.75; 9-4.25; 16-0.5; 16-3.0; 16-5.5; 23-1.75; 23-4.25; 30-0.5; 30-3.0, and 30-5.5. After the third harvest, grass roots were collected. Combination of high rates of nitrogen with low rates of calcium provided maximal dry matter yields and concentration of nitrogen in the roots. Critical levels of nitrogen and calcium in the roots of Tanzania grass were 11.07 and $1.30 \mathrm{~g} / \mathrm{kg}$, respectively. Significant correlation coefficients were found for dry mass, total length and total surface of the roots. Length and total surface and specific length and surface of the roots depend on the supply of nitrogen, but do not depend on the calcium supply. Calcium rates are determinant for this nutrient concentration in the grass roots.
\end{abstract}

Key Words: forage grass, macronutrients, Panicum maximum, root system

\section{Introdução}

Apesar da importância das raízes na produção e na persistência das pastagens, informações na literatura a respeito da produção de biomassa e dos aspectos morfológicos do sistema radicular são escassas (Bono et al., 2000) e o conhecimento sobre o efeito do manejo no ambiente em que as raízes se desenvolvem, às vezes, é controverso (Cecato et al., 2004).

Em experimentos em pastagens com avaliações do sistema radicular, apesar da importância da caracterização e dinâmica das raízes, tem sido avaliada apenas a massa seca das raízes, por ser mais facilmente obtida que o comprimento do sistema radicular (Voorhees et al., 1980). Todavia, o 
comprimento das raízes é uma variável importante no estudo de crescimento da planta, pois gera informações relativas à fisiologia e ao estado nutricional da forrageira (Eshel \& Waisel, 1996).

A absorção de nutrientes depende do crescimento contínuo do sistema radicular, uma vez que a principal área de absorção são as regiões recém-formadas ou mais jovens das raízes (Mengel \& Kirkby, 2001). A quantidade de nutrientes absorvidos pela planta é determinada pela área total de raízes e pela taxa de absorção por unidade de superfície radicular (Anghinoni \& Meurer, 1999).

O fornecimento de nutrientes afeta o crescimento e a morfologia das raízes, uma vez que o baixo fornecimento de nitrogênio produz raízes mais longas, enquanto o aumento do suprimento desse nutriente diminui o comprimento das raízes. A relação inversa entre suprimento de nitrogênio e o desenvolvimento de raízes é fenômeno bem conhecido (Bosemark, 1954; Eshel \& Waisel, 1996). O cálcio (Ca), por sua vez, está envolvido na divisão celular e, o não atendimento das exigências desse mineral nas plantas provoca inibição da extensão celular, sobretudo as radiculares, que são as primeiras a cessar o crescimento (Marschner, 1995).

A hipótese para este estudo é que o sistema radicular do Panicum maximum Jacq. cv. Tanzânia pode depender do suprimento de cálcio quando há variação na disponibilidade de nitrogênio na solução nutritiva. Objetivou-se avaliar informações sobre as alterações produtivas e morfológicas e as concentrações de nitrogênio e cálcio nas raízes de capim-tanzânia quando fertilizado com combinações de nitrogênio e cálcio.

\section{Material e Métodos}

O experimento foi realizado em casa de vegetação localizada em Piracicaba, utilizando-se a espécie Panicum maximum Jacq. cv. Tanzânia, um capim que se destaca pela sua alta produtividade e valor nutritivo quando suas exigências nutricionais são atendidas. Após 14 dias da semeadura do capim-tanzânia, foi realizada transplantação de 15 mudas de aproximadamente $3 \mathrm{~cm}$ para cada vaso plástico com capacidade de 3,6 litros, contendo sílica moída como substrato, lavada em água corrente e em água desionizada.

O capim-tanzânia foi submetido a combinações de cinco doses de nitrogênio (2; 9; 16; 23 e $30 \mathrm{mmol} / \mathrm{L})$ e cinco de cálcio (0,50; 1,75; 3,00; 4,25 e 5,50 mmol/L) em soluções nutritivas preparadas a partir da solução completa de Sarruge (1975), modificada para conter as doses proposta. De acordo com Monteiro et al. (1995), a utilização combinada de $\mathrm{N}-\mathrm{NO}_{3}{ }^{-}$e $\mathrm{N}-\mathrm{NH}_{4}{ }^{+}$melhorou o desempenho de Brachiaria brizantha cv. Marandu. Assim, procurou-se manter a proporção $\mathrm{N}^{-\mathrm{NO}_{3}}{ }_{3}^{-} \mathrm{N}^{-\mathrm{NH}_{4}}{ }^{+}$em $65 \%: 35 \%$ na solução nutritiva. A concentração de potássio (K) na solução nutritiva proposta por Sarruge (1975) é de 6,0 mmol/L e foi alterada nesse estudo para $8,0 \mathrm{mmol} / \mathrm{L}$, em razão dos resultados apresentados por Ferragine \& Monteiro (1999) para a Brachiaria decumbens e Mattos et al. (2002) para o capim-tanzânia, os quais evidenciaram a necessidade de aumentar o fornecimento de $\mathrm{K}$ para maximização do desempenho das plantas.

Empregou-se um estudo de superfície de resposta baseado em desenho experimental composto central modificado de um fatorial $5^{2}$ fracionado, de acordo com Littell \& Mott (1975). Obtiveram-se 13 combinações entre as doses dos nutrientes, em mmol/L, assim definidas: 2-0,5; 2-3,0; 2-5,5; 9-1,75; 9-4,25; 16-0,5; 16-3,0; 16-5,5; 23-1,75; 23-4,25; 30-0,5; 30-3,0 e 30-5,5. O delineamento experimental foi de blocos ao acaso, com quatro repetições.

Inicialmente forneceu-se a cada vaso um litro de solução nutritiva diluída a 25\% da concentração proposta para cada combinação entre as doses, que foi empregada por três dias, até a troca para as soluções definitivas. Desbastes periódicos das mudas foram realizados no decorrer de quatro dias até permanecerem cinco plantas por vaso. As soluções nutritivas foram renovadas a cada 14 dias, circuladas quatro vezes ao dia para a aeração das raízes, drenadas no fim do dia e fornecidas pela manhã, completando-se o volume de um litro com água desionizada.

As plantas foram submetidas a três cortes, o primeiro aos 39 dias após transplantação das mudas, o segundo aos 30 dias após o primeiro corte e o terceiro aos 28 dias após o segundo corte. No terceiro corte das plantas, as raízes foram separadas da sílica e lavadas em água corrente e água desionizada, utilizando-se duas peneiras com malhas de 0,25 e 1,00 mm. Após a separação das raízes do substrato, sub-amostras de aproximadamente $20 \%$ da massa fresca total das raízes foram coletadas de acordo com Rossielo et al. (1995) e coloridas com violeta genciana a $50 \mathrm{~g} / \mathrm{L}$, para serem digitalizadas e armazenadas em arquivo do programa Adobe Photoshop 7,0. A superfície e o comprimento total do sistema radicular foram contabilizados com o emprego do aplicativo SIARCS (Sistema Integrado para Análise de Raízes e Cobertura do Solo) versão 3,0 (Crestana et al., 1994). Para o cálculo do comprimento específico e superfície específica de raízes, procedeu-se a divisão do valor total de comprimento e de superfície radicular pela massa seca das raízes.

As raízes foram secadas em estufa com circulação forçada de ar, à temperatura de $65^{\circ} \mathrm{C}$, até massa constante, 
para a determinação da produção de massa seca das raízes, por meio de pesagem em balança de precisão. Em seguida as raízes foram processadas em moinho do tipo Wiley.

As concentrações de nitrogênio e cálcio nas raízes foram determinadas conforme metodologia descrita por Sarruge \& Haag (1974). A digestão sulfúrica e o método analítico semimicro Kjeldahl foram empregados para nitrogênio, enquanto, para a determinação de cálcio, utilizou-se a digestão nítrico-perclórica, seguida do método analítico de espectrofotometria de absorção atômica.

Os resultados foram submetidos às análises estatísticas, utilizando-se o aplicativo "Statistical Analysis System" (SAS, 1999). Executou-se inicialmente o teste F e, para casos de significância da interação doses de nitrogênio × cálcio, efetuaram-se análises de regressão polinomial (superfície de resposta) pelo procedimento RSREG. Nos casos de interação não significativa, utilizou-se o procedimento GLM para os estudos de regressão, envolvendo especificamente a dose do nutriente para a qual o efeito foi significativo pelo teste F. Adotou-se o nível de significância de 5\% em todas as análises.

\section{Resultados e Discussão}

A interação doses de nitrogênio × cálcio na solução nutritiva foi significativa para a produção de massa seca do sistema radicular do capim-tanzânia, com ajustes dos resultados ao modelo polinomial. A dose de nitrogênio que proporcionaria o máximo valor da produção de massa seca de raízes excederia a maior dose desse nutriente $(30 \mathrm{mmol} / \mathrm{L})$ e estaria associada à dose de cálcio de $4,25 \mathrm{mmol} / \mathrm{L}$. Apenas doses de cálcio inferiores a 1,75 mmol/L não permitiram alcançar a maior produção de massa seca do sistema radicular (Figura 1).

Os resultados obtidos neste experimento confirmam aqueles descritos por Lavres Junior \& Monteiro (2002) e Manarin \& Monteiro (2002) para o Panicum maximum cv. Mombaça, de Batista \& Monteiro (2006) para a Brachiaria brizantha cv. Marandu e de Santos \& Monteiro (1999) para o capim-braquiária (Brachiaria decumbens). Esses autores observaram que a produção máxima de massa seca de raízes ocorre quando utilizadas doses de nitrogênio maiores que $33 \mathrm{mmol} / \mathrm{L}$ na solução nutritiva.

Neste estudo, somente quando fornecido em baixíssimas concentrações na solução nutritiva (menor que $1,75 \mathrm{mmol} / \mathrm{L}$ ), em associação com elevadas doses de nitrogênio, o cálcio foi limitante ao crescimento das raízes, afetando a produção de massa seca radicular do capim-tanzânia. Em termos quantitativos, a exigência de cálcio é pequena, porém o nutriente deve estar presente nos pontos de crescimento

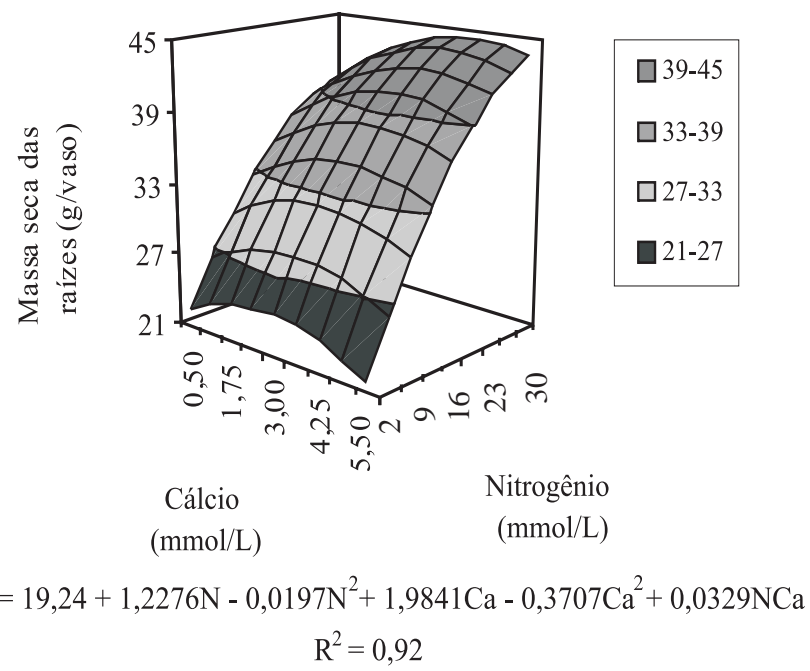

Figura 1 - Produção de massa seca de raízes do capim-tanzânia em resposta às doses de nitrogênio e cálcio na solução nutritiva.

radiculares, pois não há translocação de cálcio para as regiões meristemáticas (Mengel \& Kirkby, 2001).

O cálcio, por ser um nutriente pouco móvel na planta e manter a integridade da membrana plasmática, pode reduzir significativamente o crescimento de raízes quando não fornecido. A presença de íons de cálcio na solução ao redor das raízes mantém a seletividade dos mecanismos de transporte de íons e a sua ausência pode inibir severamente a absorção de outros íons (Marschner, 1995).

Para o comprimento e a superfície totais do sistema radicular do capim-tanzânia, não houve influência significativa da interação doses de nitrogênio $\times$ cálcio na solução nutritiva. Para ambas as características, somente as doses de nitrogênio tiveram efeitos significativos, com ajuste dos resultados ao modelo quadrático de regressão. Tanto para o comprimento total quanto para a superfície total do sistema radicular, a dose de nitrogênio que correspondeu aos valores máximos dessas duas variáveis foi de $27,46 \mathrm{mmol} / \mathrm{L}$ e de $29,58 \mathrm{mmol} / \mathrm{L}$, respectivamente (Figura 2).

Lavres Junior \& Monteiro (2003), avaliando o comprimento total e a superfície total de raízes de capimmombaça adubado com combinações de nitrogênio e potássio na solução nutritiva, concluíram que, para obtenção dos valores máximos dessas variáveis, seria necessário fornecimento de nitrogênio em doses mais elevadas que a máxima utilizada no experimento (33 mmol/L), de forma similar aos resultados do presente experimento. Esses resultados reforçam a afirmação de Marschner (1995), de que o suprimento de nutrientes pode afetar fortemente o 

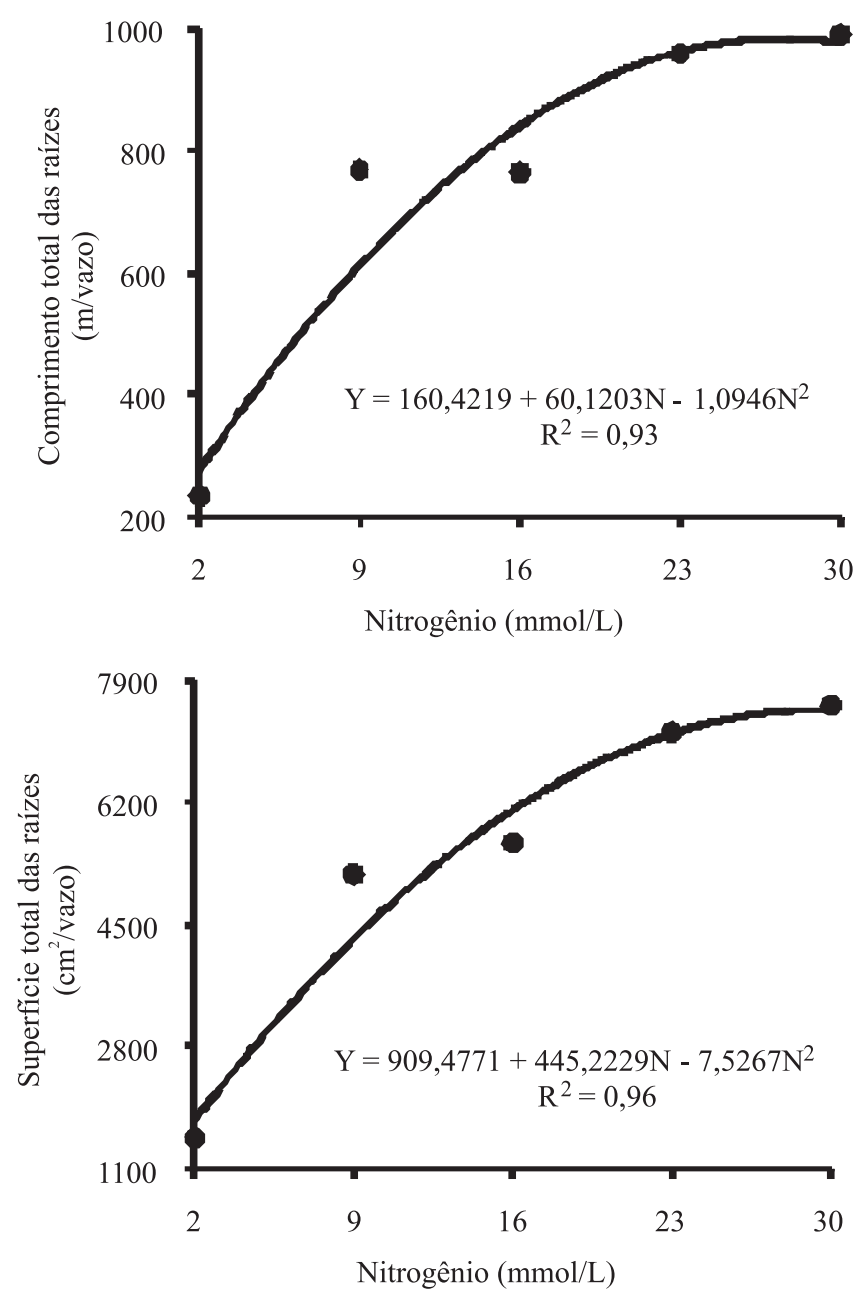

Figura 2 - Comprimento e superfície total das raízes de capimtanzânia em resposta às doses de nitrogênio na solução nutritiva.

crescimento e a distribuição do sistema radicular no substrato e que este efeito é marcado principalmente pelo nitrogênio.

A interação doses de nitrogênio $\times$ cálcio não foi significativa para comprimento e superfície específicos do sistema radicular. Entretanto, houve efeito significativo das doses de nitrogênio em ambas as características, com ajustes dos resultados ao modelo quadrático de regressão. A dose de nitrogênio que proporcionou o menor valor foi de $25,02 \mathrm{mmol} / \mathrm{L}$ para o comprimento específico e de 23,96 mmol/L para a superfície específica (Figura 3). Essa variação de pequena amplitude (menos de $3 \mathrm{mmol} / \mathrm{L}$ ) nas doses necessárias de nitrogênio para proporcionar o mínimo nesses parâmetros radiculares foi semelhante à obtida por Lavres Junior \& Monteiro (2003) em experimento no qual estudaram o suprimento de nitrogênio e potássio na solução nutritiva e observaram o valor mínimo de comprimento específico e de superfície específica das raízes nas doses de nitrogênio de 23,43 e 20,79 mmol/L, respectivamente.
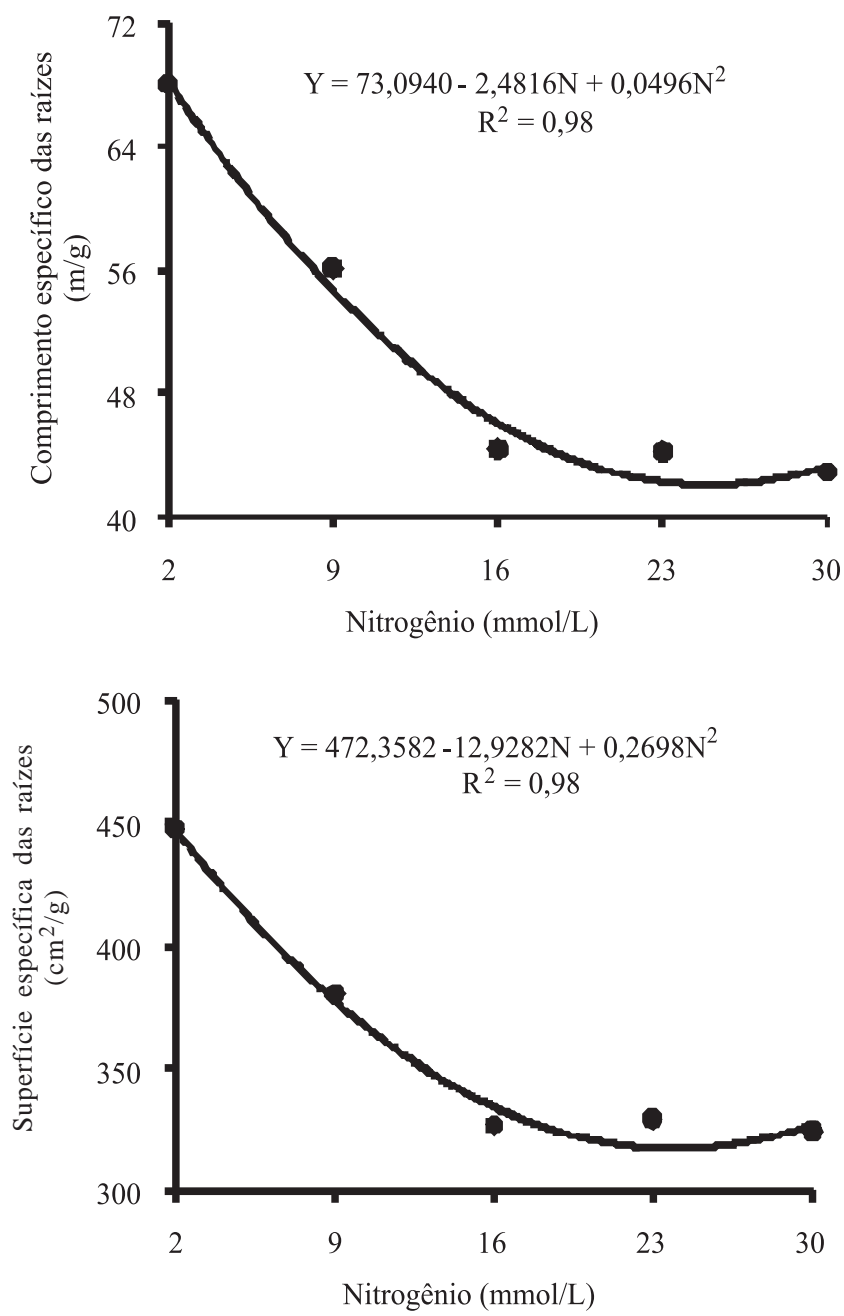

Figura 3 - Comprimento e superfície específica das raízes do capim-tanzânia em resposta às doses de nitrogênio na solução nutritiva

Quando o nitrogênio foi fornecido em baixa concentração, tanto o comprimento específico quanto a superfície específica foram maiores, ou seja, o diâmetro médio das raízes diminuiu até certo ponto (presença de raízes mais finas) com o aumento no suprimento de nitrogênio. Segundo Fitter (1996), essa resposta é um mecanismo da planta para aumentar a área de exploração das raízes e absorver mais nutrientes quando submetida à carência nutricional, o que justifica os resultados desta pesquisa, pois o maior comprimento específico das raízes do capim-tanzânia correspondeu à mais baixa dose de nitrogênio ( $2 \mathrm{mmol} / \mathrm{L}$ ).

A interação nitrogênio $\times$ cálcio foi significativa para a concentração de nitrogênio nas raízes de capim-tanzânia. O resultado ajustou-se ao modelo polinomial, de modo que a menor dose de nitrogênio (2 $\mathrm{mmol} / \mathrm{L}$ ), quando associada à dose de cálcio de $1,75 \mathrm{mmol} / \mathrm{L}$, proporcionou a mais baixa concentração de nitrogênio nas raízes do capim-tanzânia. A concentração de nitrogênio nas raízes 
dessa gramínea variou entre 8,11 e 15,52 g/kg (Figura 4). Resultados semelhantes foram obtidos por Manarin \& Monteiro (2002) em capim-mombaça adubado com solução nutritiva contendo nitrogênio. Esses autores verificaram que a concentração de nitrogênio nas raízes dessa gramínea variou entre 8,2 e $18,6 \mathrm{~g} / \mathrm{kg}$, dentro dos limites previstos para as doses estudadas.

O aumento nas concentrações de nitrogênio nas raízes, promovido pelas doses mais altas desse nutriente, pode ser favorável ao capim após o corte das plantas. Isso se deve ao fato que, de todo o nitrogênio presente na parte aérea formada na primeira semana após o corte das plantas, $80 \%$ pode ser proveniente da translocação do nitrogênio a partir das raízes e dos colmos e o restante proveniente da absorção de nitrogênio (Chapman \& Lemaire, 1996). Assim, o suprimento de nitrogênio para a parte aérea (Silveira \& Monteiro, 2010) fica dependente de um sistema radicular mais desenvolvido.

As concentrações de nitrogênio nas raízes do capimtanzânia foram mínimas na dose de nitrogênio de $2 \mathrm{mmol} / \mathrm{L}$ e aumentaram conforme as doses desse nutriente na solução nutritiva. Esse resultado indica que dose de nitrogênio no substrato inferior a $2 \mathrm{mmol} / \mathrm{L}$ não promove acúmulo de nitrogênio nos tecidos das raízes. O nível crítico (correspondente a 90\% da produção máxima de massa seca das raízes) de nitrogênio nas raízes do capim-tanzânia estabelecido neste experimento foi de $11,07 \mathrm{~g} / \mathrm{kg}$. Pode-se afirmar que, abaixo desse valor, as raízes devem sofrer redução no seu crescimento, por meio da deficiência de nitrogênio e, consequentemente, pode ocorrer queda na produtividade.

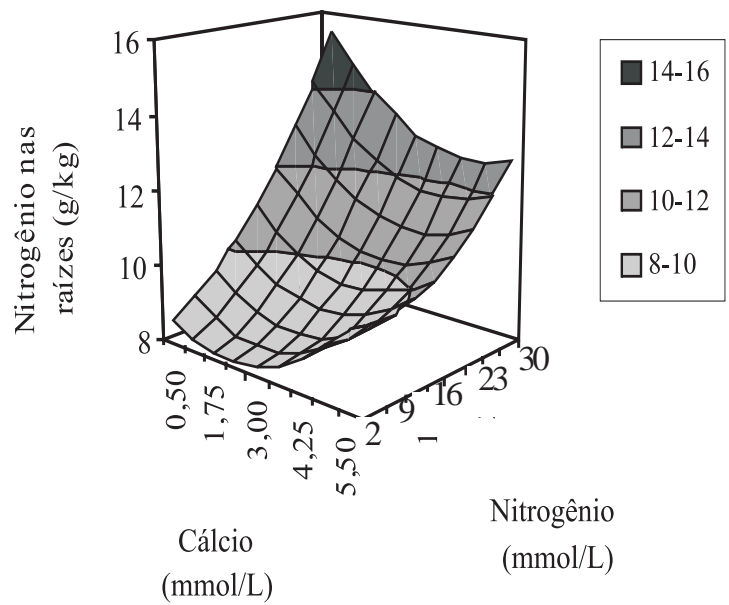

$$
\begin{gathered}
\mathrm{Y}=8,8059+0,0898 \mathrm{~N}+0,0053 \mathrm{~N}^{2}-0,7550 \mathrm{Ca}+0,1836 \mathrm{Ca}^{2}-0,0298 \mathrm{NCa} \\
\mathrm{R}^{2}=0,59
\end{gathered}
$$

Figura 4 - Concentração de nitrogênio nas raízes de capim-tanzânia em resposta às combinações nitrogênio e cálcio na solução nutritiva.
A concentração de cálcio nas raízes do capim-tanzânia sofreu influência significância da interação nitrogênio × cálcio na solução nutritiva. Efeitos significativos das doses de cálcio foram observados na concentração desse nutriente nas raízes, com ajuste dos resultados ao modelo linear de regressão. A concentração de cálcio nas raízes do capimtanzânia variou de 1,08 a 2,22 g/kg da menor para a maior dose de cálcio nas soluções nutritivas (Figura 5). Variação semelhante na concentração desse nutriente nas raízes do capim-tanzânia foi observada por Monteiro \& Consolmagno Neto (2008). Essas concentrações são consideradas adequadas, uma vez que a concentração crítica de cálcio nas raízes estabelecida neste experimento para o adequado crescimento do capim-tanzânia foi de 1,30 g/kg. Esse nível crítico ocorreu quando o cálcio foi fornecido na solução nutritiva em concentrações muito inferiores à de $5 \mathrm{mmol} / \mathrm{L}$ recomendada por Sarruge (1975).

As raízes de capim-tanzânia estavam com deficiência de cálcio (concentrações inferiores ao nível crítico de cálcio de $1,30 \mathrm{~g} / \mathrm{kg}$ ) apenas quando se forneceram as doses de $0,5 \mathrm{e}$ 1,75 mmol/L desse nutriente, também responsáveis pela redução na produção de massa seca do sistema radicular (Figura 1). Essa deficiência de cálcio no sistema radicular reduziu o crescimento das regiões meristemáticas das raízes (ápices radiculares) e, consequentemente, a superfície dos pêlos radiculares, reduzindo a capacidade de absorção de água e nutrientes para adequada produção de massa foliar, fator imprescindível para a manutenção de pastagens.

Correlações entre as variáveis do sistema radicular do capim-tanzânia foram avaliadas, porém, somente para

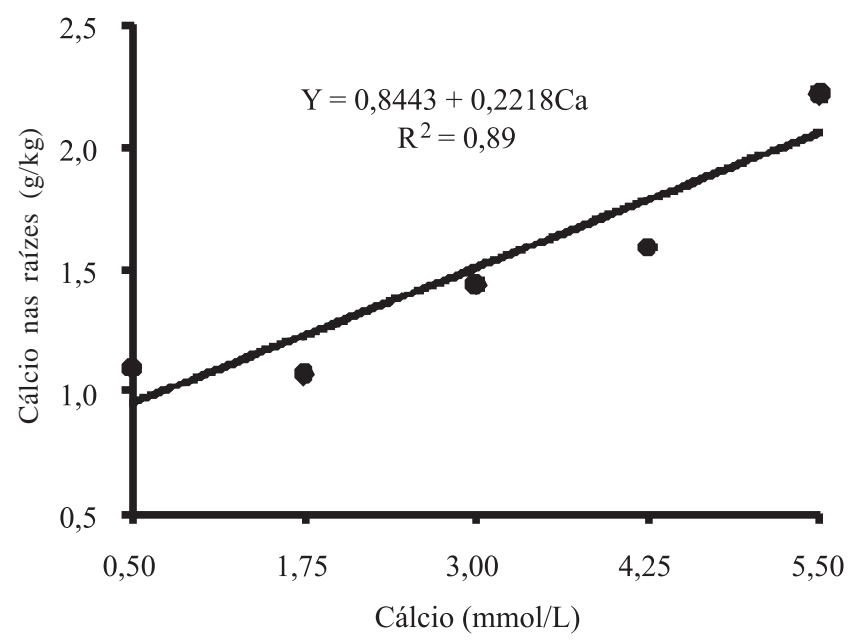

Figura 5 - Concentração de cálcio nas raízes de capim-tanzânia em resposta às doses de cálcio. 
comprimento total, superfície total e massa seca das raízes, os coeficientes de correlação foram significativos. A produção de massa seca das raízes correlacionou-se positivamente com o comprimento total $(r=0,85)$ e com a superfície total $(\mathrm{r}=0,93)$ e o comprimento total positivamente com a superfície total das raízes $(r=0,95)$. Elevados coeficientes de correlação entre essas características eram esperados, uma vez que o desenvolvimento do sistema radicular pode ser medido pelo aumento do comprimento total, que resulta em maior área superficial total e, consequentemente, maior produção de massa seca de raízes. Resultados semelhantes também foram observados por Batista \& Monteiro (2006) em estudo do sistema radicular de capim-marandu fertilizado com combinações de nitrogênio e enxofre.

\section{Conclusões}

A combinação de elevadas doses de nitrogênio com doses relativamente baixas de cálcio permite obter valores máximos de produção de massa seca e concentração de nitrogênio nas raízes do capim-tanzânia. O comprimento total e a superfície total das raízes, bem como o comprimento específico e a superfície específica, dependem do fornecimento de nitrogênio, não de cálcio.

\section{Referências}

ANGHINONI, I.; MEURES, E.J. Eficiência de absorção de nutrientes pelas raízes. In: WORKSHOP SOBRE SISTEMA RADICULAR: metodologias e estudo de casos, Aracaju, 1999. Anais... Aracaju: EMBRAPA Tabuleiros Costeiros, 1999. 300p.

BATISTA, K.; MONTEIRO, F.A. Sistema radicular do capimMarandu, considerando as combinações de doses de $\mathrm{N}$ e de enxofre. Revista Brasileira de Ciência do Solo, v.30, n.1, p.821-828, 2006.

BONO, J.A.; MACEDO, M.C.M.; EUCLIDES, V.B.P. Biomassa e área do sistema radicular e resistência do solo a penetração em pastagens de Panicum maximum Jacq. sob pastejo rotacionado. In: REUNIÃO ANUAL DA SOCIEDADE BRASILEIRA DE ZOOTECNIA, 37., 2000, Viçosa, MG. Anais... Viçosa, MG: Sociedade Brasileira de Zootecnia, 2000. (CD-ROM).

BOSEMARK, N.O. The influence of nitrogen on root development. Physiologia Plantarum, v.7, n.1, p.497-502, 1954.

CECATO, U.; JOBIM, C.C.; REGO, F.C.A. et al. Sistema radicular - componente esquecido das pastagens. In: SIMPÓSIO SOBRE MANEJO ESTRATÉGICO DA PASTAGEM, 2., 2004, Viçosa, MG. Anais... Viçosa, MG: Universidade Federal de Viçosa, 2004. p.159-207.

CHAPMAN, D.; LEMAIRE, G. Tissue flows in grazed plant communities. In: HODGSON, J.; ILLIUS, A.W. (Eds.). The ecology and management of grazing systems. Guilford: CAB International, 1996. p.3-36.

CRESTANA, S.; GUIMARÃES, M.F.; JORGE, L.A.C. et al. Avaliação da distribuição de raízes no solo auxiliada por processamento de imagens digitais. Revista Brasileira de Ciência do Solo, v.18, n.3, p.365-371, 1994.

ESHEL, A.; WAISEL, Y. Multiform and multifunction of various constituents o fone root system. In: WAISEL, Y.; ESHEL, A.; KAFKAFI, U. (Eds.). Plant roots: the hidden half. 2.ed. New York: Marcel Dekker, 1996. p.175-192.

FERRAGINE, M.D.C.; MONTEIRO, F.A. Combinações de doses de $\mathrm{N}$ e potássio na nutrição mineral de capim-braquiária. Boletim de Indústria Animal, v.56, n.1, p.25-33, 1999.

FITTER, A. Characteristics and functions of root systems. In: WAISEL, Y.; ESHEL, A.; KAFKAFI, U. (Eds.). Plants roots: the ridden half. New York: Marcel Dekker, 1996. p.1-20.

LAVRES JUNIOR, J.; MONTEIRO, F.A. Perfilhamento, área foliar e sistema radicular do capim-Mombaça submetido a combinações de doses de $\mathrm{N}$ e potássio. Revista Brasileira de Zootecnia, v.32, n.1, p.1068-1075, 2003.

LAVRES JUNIOR, J.; MONTEIRO, F.A. Combinações de doses de $\mathrm{N}$ e potássio para a produção e nutrição do capim-Mombaça. Boletim de Indústria Animal, v.59, n.1, p.102-114, 2002.

LITTELL, R.C.; MOTT, G.O. Computer assisted design and analysis of response surface experiments in agronomy. Soil and Crop Society of Florida Proceedings, v.34, n.5, p.94-97, 1975.

MANARIN, C.A.; MONTEIRO, F.A. N na produção e diagnose foliar do capim-Mombaça. Boletim de Indústria Animal, v.59, n.1, p.115-123, 2002.

MARSCHNER, H. Mineral nutrition of higher plants. London: Academic Press, 1995. 889p.

MATTOS, W.T.; SANTOS, A.R.; ALMEIDA, A.A.S. et al. Aspectos produtivos e diagnose nutricional do capim-tanzânia submetido a doses de potássio. Magistra, v.14, n.1, p.37-44, 2002.

MENGEL, K.; KIRKBY, E.A. Principles of plant nutrition. Dordrechth: Kluwer Academic Publishers, 2001. 849p.

MONTEIRO, F.A.; CONSOLMAGNO NETO, D. Sistema radicular do capim-tanzânia adubado com potássio e magnésio. Revista Brasileira de Zootecnia, v.37, n.5, p.810-818, 2008.

MONTEIRO, F.A.; RAMOS, A.K.B.; CARVALHO, D.D. et al. Cultivo de Brachiaria brizantha Stapf. cv. Marandu em solução nutritiva com omissões de macronutrientes. Scientia Agricola, v.52, n.1, p.135-141, 1995.

ROSSIELlO, R.O.P.; ARAÚJO, A.P.; MANZATTO, C.V. et al. Comparação dos métodos fotoelétrico e da interseção na determinação de área, comprimento e raio médio radicular. Pesquisa Agropecuária Brasileira, v.30, n.5, p.633-638, 1995.

SANTOS, A.R.; MONTEIRO, F.A. Produção e perfilhamento de Brachiaria decumbens Stapf. em função de doses de enxofre. Scientia Agricola, v.56, n.1, p.689-692, 1999.

SARRUGE, J.R. Soluções nutritivas. Summa Phytopathologica, v.1, n.3, p.231-233, 1975.

SARRUGE, J.R.; HAAG, H.P. Análises químicas em plantas. Piracicaba: Escola Superior de Agricultura "Luiz de Queiroz", Departamento de Química, 1974. 54p.

SILVEIRA, C.P.; MONTEIRO, F.A. Macronutrientes em folhas diagnósticas do capim-tanzânia adubado com nitrogênio e cálcio. Revista Brasileira de Zootecnia, v.39, n.4, p.736-745, 2010.

STATISTICAL ANALYSIS SYSTEM - SAS. User's guide statistics: version 8.0 edition. Cary: SAS Institute, 1999. 956p.

VOORHESS, W.B.; CARLSON, V.A.; HALLAUER, E.A. Root length measurement with a computer-controlled digital scanning microdensitometer. Agronomy Journal, v.72, n.2, p.847-850, 1980. 